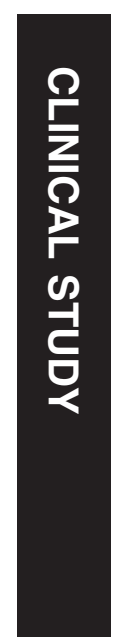

\section{The development and evolution of full thickness macular hole in highly myopic eyes}

C-W Lin, T-C Ho and C-M Yang

\section{Introduction}

Department of

Ophthalmology, National

Taiwan University Hospital, Taipei, Taiwan

Correspondence:

C-M Yang, Department of Ophthalmology, National

Taiwan University Hospital; College of Medicine, National Taiwan University; No.7, Chung-Shan South Road, Taipei 100, Taiwan. Tel: +886223123456 ext 65187;

Fax: +886 223934420

E-mail: chungmay@

ntu.edu.tw

Received: 26 May 2014 Accepted in revised form: 28 October 2014

Published online:

9 January 2015

\begin{abstract}
Purpose To evaluate the morphological changes before and after the formation of a full-thickness macular hole (MH) in highly myopic eyes.

Patients and methods Retrospective observational case series. From 2006 to 2013, clinical records of patients with $\mathrm{MH}$ and high myopia who had optical coherence tomography (OCT) before the development of $\mathrm{MH}$ were reviewed. All patients had been followed for more than 1 year since MH formation to observe the morphological changes.

Results Twenty-six eyes of 24 patients were enrolled. The initial OCT images could be classified into four types: (1) normal foveal depression with abnormal vitreo-retinal relationship (eight cases), (2) macular schisis without detachment (six cases), (3) macular schisis with concomitant/subsequent detachment (nine cases), and (4) macular atrophy with underlying/adjacent scar (three cases). After MH formation, one case in type 1 and one case in type 4 group developed retinal detachment (RD). In type 2 group, four cases developed RD at the same time of MH formation. The preexisting detachment in type 3 group extended in eight cases and improved in one case. Among all the cases, 14 eyes received vitrectomy and 7 eyes received gas injection. $\mathrm{MH}$ sealed in nine eyes after vitrectomy and four eyes by gas injection.

Conclusion The study revealed four pathways of MH formation in highly myopic eyes. MH from macular schisis tended to be associated with detachment. However, the evolution and the results of surgical intervention were not always predictable. Eye (2015) 29, 388-396; doi:10.1038/eye.2014.312; published online 9 January 2015
\end{abstract}

Full thickness macular hole (FTMH) most commonly occurs in older patients without an apparent underlying cause. ${ }^{1}$ It may also develop after ocular trauma ${ }^{2}$ or in association with high myopia, rhegmatogenous retinal detachment (RD), or diabetic retinopathy. ${ }^{3}$ Extensive studies by optical coherence tomography (OCT) confirm that the formation of idiopathic macular hole (MH) is usually associated with vitreofoveal traction, or less frequently with epiretinal membrane. ${ }^{1,4}$ High myopia has a high prevalence in Taiwan, ${ }^{5}$ with $\mathrm{MH}$ being one of the frequently seen complications of myopic maculopathy.

However, the pathogenesis of $\mathrm{MH}$ formation in highly myopic eyes remains incompletely understood. A literature review reveals that the formation of $\mathrm{MH}$ in high myopia involves complex traction forces from various directions, including vitreous anterior-posterior traction, oblique or tangential traction from partially or undetached posterior hyaloid, traction from epiretinal membrane, internal limiting membrane (ILM) induced tangential traction, posterior outward traction from the staphyloma, and retinal vessel traction. ${ }^{6-11}$ These factors, alone or in combination, may induce $\mathrm{MH}$ formation through mechanisms different from those underlying idiopathic $\mathrm{MH}$. Before the $\mathrm{MH}$ formation, the macula may have normal configuration, may show schisis cavity, or may develop schisis with subfoveal detachment. Foveoschisis is believed to be one of the main causes of $\mathrm{MH}$ formation in highly myopic eyes, ${ }^{12-14}$ and is often found in combination with foveal detachment, lamellar $\mathrm{MH}(\mathrm{LMH})$, and vitreomacular traction. Although the development of $\mathrm{MH}$ from schisis with foveal detachment has been reported, ${ }^{15}$ 
the development of MH through other pathways and the evolution of $\mathrm{MH}$ after its formation have not yet been described in detail. In this study, by examining sequential OCT images, we investigated the various mechanisms of the formation of $\mathrm{MH}$ and the possible alterations of the retinal structure after $\mathrm{MH}$ development in high myopic patients.

\section{Materials and methods}

\section{Subjects}

From September 2006 to September 2013, clinical records of OCT-verified FTMH from National Taiwan University Hospital were retrospectively reviewed. Cases with OCT studies before the development of FTMH were selected. All included cases had a refractive error of more than six diopters or an axial length of more than $26 \mathrm{~mm}$, and all cases were followedup for more than 1 year after the development of FTMH. The study was conducted according to the tenets of the Declaration of Helsinki and was approved by the Research Ethics Committee of National Taiwan University Hospital.

\section{Ocular examinations and follow-up}

Ophthalmoscopic examinations, best-corrected visual acuity, refraction status (Auto Refractometer KR-8800, Topcon Corporation, Tokyo, Japan), axial length measured by ultrasound (PAC Scan 300AP, Sonomed Inc., NY, USA), and OCT examinations (Cirrus HD-OCT 400, Carl Zeiss Meditec, Dublin, CA, USA; RTVue OCT RT100 Optovue, Fremont, CA, USA; Stratus OCT 3000, Carl Zeiss Meditec) were recorded in all the patients. Axial length was measured while the retina was attached. OCT studies were regularly done every 3-6 months depending on the severity of the macular changes. The OCT features were obtained by multiple scans centered on the fovea. The scan length was $8-10 \mathrm{~mm}$. The changes of vitreomacular relationship in OCT examination and the status of posterior staphyloma were also analyzed. Posterior staphyloma was defined as ectasia in the posterior pole detected in the OCT and fundus photographs. Ophthalmological examinations including best-corrected visual acuity, biomicroscopy, and indirect ophthalmoscopy were performed at an interval of 3-6 months. We performed gas injection initially for the cases of $\mathrm{MH}$ with localized RD in the posterior retina (not extended beyond the equator) and no OCT visible traction. ${ }^{16,17}$ For the cases with extensive RD or OCT visible traction, vitrectomy was indicated. The procedures or operations the patients received were also recorded.

\section{Surgical procedures}

Gas injection After proper disinfection and anterior chamber paracentesis, intravitreal injection of $0.2-0.4 \mathrm{ml}$ $\mathrm{C}_{3} \mathrm{~F}_{8}$ was performed. A 27-gauge needle was used to make the injection through temporal upper or lower pars plana, $3.5 \mathrm{~mm}$ posterior to the limbus. The patients were subsequently kept in a head down position for approximately 1 week.

Vitrectomy Standard 3-port 20 or 23 gauged pars plana vitrectomy was performed. After core vitrectomy and triamcinolone acetonide-assisted (TA, $2.5 \mathrm{mg} / \mathrm{ml}$ ) posterior hyaloid removal, posterior retina was carefully inspected to identify any preretinal membrane. Forceps removal of the membrane (if present) was performed, followed by Indocyanine green (ICG)-assisted ILM peeling. To avoid the potential toxicity of ICG to the RPE, in those cases without macular detachment, a small amount of VisCoat (Alcon-Couvreur N.V., Rijksweg, Puurs, Belgium) was placed in the hole to prevent the ICG from contacting the RPE later in the procedure. ${ }^{18,19}$ ICG was diluted to a low concentration with $15 \mathrm{ml} \mathrm{5 \%}$ glucose water (concentration of ICG: $1.7 \mathrm{mg} / \mathrm{ml}$ ) and then carefully applied around the hole. As the solution had a higher gravity than that of water, it could be applied in a more controlled manner. The excessive ICG solution was immediately removed by suction. VisCoat was aspirated from the hole after good ILM staining. The non-stained area indicated the presence of taut epiretinal membrane (ERM). Direct forceps grasping was then used to create an ILM break. ILM peeling along with the overlying ERM (if present) for at least 4 disc diameter centering on the fovea was performed in a circular manner. The peripheral retina was then examined for possible breaks, followed by air-fluid exchange and 15\% $\mathrm{C}_{3} \mathrm{~F}_{8}$ infusion into the vitreous cavity. The patients were subsequently kept in a prone position for approximately 1 week.

\section{Statistical analysis}

The relationship between the type of $\mathrm{MH}$ formation and axial length was analyzed by ANOVA. The correlation between axial length and initial anatomic success after vitrectomy or gas injection was evaluated by binary logistic regression. Statistical analysis was analyzed by the SPSS (version 17.0, SPSS Inc., Chicago, IL, USA).

\section{Results}

The demographic data and clinical characteristics of all study eyes are shown in the Table 1 . In total, 26 eyes from 24 patients (5 men and 19 women) were enrolled in this study. 
Table 1 The demographic data and clinical characteristics of all the eyes

\begin{tabular}{|c|c|c|c|c|c|c|c|c|c|c|c|c|}
\hline No & Sex & Age & $R / L$ & $\begin{array}{l}\text { Refraction } \\
\text { (D) }\end{array}$ & $\begin{array}{l}A x L \\
(\mathrm{~mm})\end{array}$ & Staphyloma & Initial OCT & $\begin{array}{l}\text { Initial } \\
B C V A\end{array}$ & $\begin{array}{c}B C V A \\
\text { after } M H\end{array}$ & Operation & Final OCT & $\begin{array}{l}\text { Final } \\
\text { BCVA }\end{array}$ \\
\hline 1 & $\mathrm{~F}$ & 53 & $\mathrm{~L}$ & -6.1 & 25.86 & $\mathrm{Y}$ & Impending $\mathrm{MH}$ & $20 / 40$ & $20 / 50$ & PPV & Sealed & $20 / 32$ \\
\hline 2 & $\mathrm{~F}$ & 55 & $\mathrm{R}$ & PCIOL & 34.1 & $\mathrm{Y}$ & LMH & $20 / 40$ & $20 / 125$ & PPV & MH & $20 / 2000$ \\
\hline 3 & $\mathrm{~F}$ & 60 & $\mathrm{~L}$ & PCIOL & 30.7 & $\mathrm{Y}$ & LMH & $20 / 400$ & $20 / 800$ & PPV & $\mathrm{MH}$ & $20 / 125$ \\
\hline 4 & $\mathrm{~F}$ & 60 & $\mathrm{~L}$ & -7.25 & 26.34 & $\mathrm{~N}$ & LMH & $\mathrm{ND} 30 \mathrm{~cm}$ & $\mathrm{ND} 10 \mathrm{~cm}$ & & $\mathrm{MH}$ & $\mathrm{HM} 30 \mathrm{~cm}$ \\
\hline 5 & $\mathrm{~F}$ & 57 & $\mathrm{~L}$ & -14.3 & 29.15 & $\mathrm{Y}$ & LMH & $20 / 63$ & $20 / 63$ & PPV & MH & 20/125 \\
\hline 6 & $\mathrm{~F}$ & 57 & $\mathrm{R}$ & PCIOL & 31.9 & $\mathrm{Y}$ & LMH & $20 / 50$ & $20 / 63$ & & MH & $20 / 63$ \\
\hline 7 & $\mathrm{M}$ & 53 & $\mathrm{~L}$ & -13.63 & 29.38 & $\mathrm{Y}$ & LMH & $20 / 25$ & $20 / 100$ & PPV & Sealed & $20 / 32$ \\
\hline 8 & $\mathrm{M}$ & 59 & $\mathrm{~L}$ & -14.75 & 31.77 & $\mathrm{Y}$ & $\mathrm{LMH}$ & $20 / 50$ & $20 / 125$ & PPV & Sealed & $20 / 200$ \\
\hline 9 & $\mathrm{~F}$ & 61 & $\mathrm{R}$ & -19.75 & 31.98 & $\mathrm{Y}$ & Schisis & $\mathrm{HM} 20 \mathrm{~cm}$ & $\mathrm{HM} 20 \mathrm{~cm}$ & & $\mathrm{MH}$ & $20 / 2000$ \\
\hline 10 & $\mathrm{~F}$ & 62 & $\mathrm{R}$ & -22.75 & 29.05 & $\mathrm{Y}$ & Schisis & $20 / 63$ & $20 / 400$ & PPV & Sealed & $20 / 400$ \\
\hline 11 & $\mathrm{~F}$ & 72 & $\mathrm{~L}$ & aphakia & 29.65 & Y & Schisis & $20 / 40$ & $20 / 200$ & PPV & Sealed & $20 / 63$ \\
\hline 12 & $\mathrm{~F}$ & 40 & $\mathrm{R}$ & -11.75 & 29.71 & $\mathrm{Y}$ & Schisis & $20 / 32$ & $20 / 125$ & PPV & $\mathrm{MH}$ & $20 / 125$ \\
\hline 13 & $\mathrm{~F}$ & 67 & $\mathrm{R}$ & -12.25 & 30.49 & $\mathrm{Y}$ & Schisis & $20 / 800$ & $20 / 800$ & Gas & Sealed & $20 / 800$ \\
\hline 14 & $\mathrm{M}$ & 56 & $\mathrm{R}$ & -16 & 26.99 & $\mathrm{Y}$ & Schisis & $20 / 100$ & $20 / 400$ & PPV & $\mathrm{MH}$ & $20 / 400$ \\
\hline 15 & $\mathrm{~F}$ & 60 & $\mathrm{~L}$ & PCIOL & 30.41 & $\mathrm{Y}$ & Schisis & $20 / 63$ & $20 / 63$ & Gas & Mild Schisis & $20 / 63$ \\
\hline 16 & $\mathrm{~F}$ & 54 & $\mathrm{~L}$ & -14.25 & 30.29 & $\mathrm{Y}$ & Schisis RD & $20 / 400$ & $20 / 400$ & PPV & MH, mild Schisis & $20 / 100$ \\
\hline 17 & $\mathrm{~F}$ & 70 & $\mathrm{R}$ & PCIOL & 27.45 & $\mathrm{Y}$ & Schisis RD & $20 / 100$ & $20 / 100$ & Gas & Schisis & $20 / 63$ \\
\hline 18 & $\mathrm{~F}$ & 85 & $\mathrm{~L}$ & PCIOL & 29.03 & Y & Schisis RD & $20 / 400$ & $20 / 400$ & Gas & LMH Schisis & $20 / 400$ \\
\hline 19 & $\mathrm{~F}$ & 66 & $\mathrm{R}$ & -19 & 31.83 & $\mathrm{Y}$ & Schisis & $20 / 50$ & $20 / 400$ & PPV & Sealed & $20 / 200$ \\
\hline 20 & M & 65 & $\mathrm{R}$ & PCIOL & 29.67 & $\mathrm{Y}$ & Schisis RD & $20 / 200$ & $\mathrm{ND} 30 \mathrm{~cm}$ & Gas & $\mathrm{MH}$ & $\mathrm{HM}^{\mathrm{a}} 20 \mathrm{~cm}$ \\
\hline 21 & $\mathrm{~F}$ & 56 & $\mathrm{~L}$ & -19 & 31.72 & $\mathrm{Y}$ & Schisis RD & $20 / 200$ & $20 / 200$ & Gas & $\mathrm{MH}$ & $20 / 800$ \\
\hline 22 & M & 46 & $\mathrm{~L}$ & -20.87 & 35.26 & $\mathrm{Y}$ & Schisis RD & $20 / 40$ & $\mathrm{ND} 30 \mathrm{~cm}$ & $\mathrm{PPV}+\mathrm{SB}$ & $\mathrm{MH}^{\mathrm{b}}$ & $20 / 400$ \\
\hline 23 & $\mathrm{~F}$ & 66 & $\mathrm{R}$ & PCIOL & 29.36 & $\mathrm{Y}$ & Schisis RD & $20 / 50$ & $20 / 400$ & PPV & Sealed RD & $20 / 125$ \\
\hline 24 & $\mathrm{~F}$ & 60 & $\mathrm{R}$ & -18.5 & 31.11 & $\mathrm{Y}$ & Scar & ND20cm & $\mathrm{HM} 20 \mathrm{~cm}$ & & MH & $\mathrm{HM} 20 \mathrm{~cm}$ \\
\hline 25 & $\mathrm{~F}$ & 61 & $\mathrm{~L}$ & -23.87 & 30.4 & $\mathrm{Y}$ & Scar & $20 / 200$ & $20 / 200$ & Gas & $\mathrm{MH}$ & $20 / 2000$ \\
\hline 26 & $\mathrm{~F}$ & 61 & $\mathrm{~L}$ & PCIOL & 31.47 & $\mathrm{Y}$ & Scar & $20 / 200$ & $20 / 200$ & & $\mathrm{MH}$ & $20 / 200$ \\
\hline Average & & 60 & & -15.87 & 30.2 & & & & & & & \\
\hline
\end{tabular}

Abbreviations: AxL, axial length; BCVA, best-corrected visual acuity; HM, hand motion; LMH, lamellar macular hole; MH, macular hole; ND, number of digit; OCT, optical coherence topography; PCIOL, posterior chamber intraocular lens; PPV, pars plana vitrectomy; RD, retinal detachment; SB, scleral buckling.

${ }^{\text {a }}$ Macular hole sealed initially but reopened 15 months later.

${ }^{\mathrm{b}}$ Macular hole sealed initially but reopened 34 months later.

The mean age was $60 \pm 8.55$ years (range: $40-85$ ). The mean refractive error was $-15.87 \pm 5.09$ diopters (range: -6.10 to -23.87 diopter) and the mean axial length was $30.2 \pm 2.14 \mathrm{~mm}$ (range: $25.86-35.26 \mathrm{~mm}$ ). All except one eye (case 4) had staphylomata. The initial OCT changes of the study eyes could be classified into 4 types: (1) normal foveal depression with abnormal vitreoretinal relationship, (2) macular schisis without macular detachment, (3) macular schisis with concomitant or subsequent macular detachment, and (4) macular atrophy with underlying or adjacent submacular scar.

\section{Development of FTMH}

Type 1: Normal foveal depression with an abnormal vitreoretinal relationship (1) Abnormal vitreofoveal adhesion with vitreo-macular separation: one case belonged to this type (case 1). The axial length was $25.86 \mathrm{~mm}$. It showed similar macular changes as those in idiopathic $\mathrm{MH}$ formation (Figures 1a-d). The vitreo-foveal traction induced intraretinal cystic changes and outer laminar dehiscence. FTMH was noted within 1 week after the initial changes were detected.

(2) Tangential premacular traction from an ERM: seven cases belonged to this type (cases $2-8$ ). The average axial length was $30.47 \pm 2.48 \mathrm{~mm}$ (range: $26.34-34.1 \mathrm{~mm}$ ). $\mathrm{LMH}$ was noted initially in all cases. Tangential traction exerted from the surrounding ERM led to the formation of $\mathrm{MH}$ (Figures $1 \mathrm{e}-\mathrm{g}$ ). It took $24.8 \pm 24.4$ months on average (range: $0.5-75$ months) to develop $\mathrm{MH}$ from $\mathrm{LMH}$.

Type 2: Macular schisis without macular detachment Six eyes belonged to this type (cases 9-14). The average axial length was $29.65 \pm 1.65 \mathrm{~mm}$ (range: $29.05-31.98 \mathrm{~mm}$ ). All cases developed inner LMH before continuous tangential traction caused outer laminar disruption and FTMH (cases 9, 11-14) (Figures 2a-e). It took 8, 32, 18, 49, 12, and 43 months, respectively, (average: $27 \pm 16.9$ months, range: $8-49$ months) to develop $\mathrm{MH}$ from schisis without RD. The interval from $\mathrm{LMH}$ to $\mathrm{MH}$ was $13.33 \pm 12.06$ months $(8,6,18,1,12$, and 35 months, respectively). 


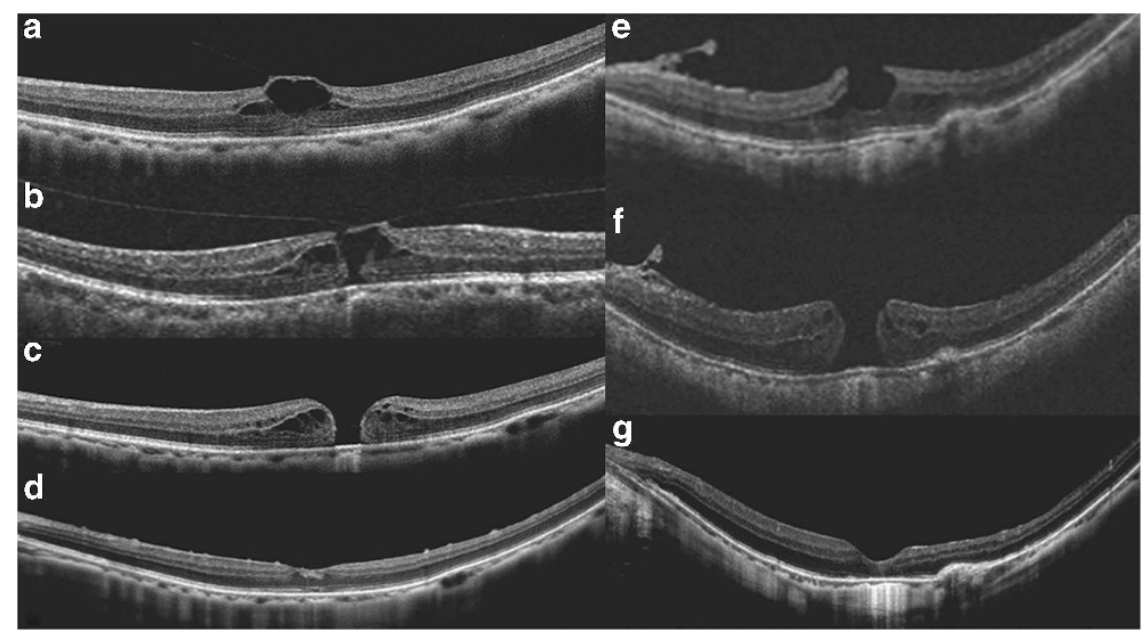

Figure 1 (a-d) Case 1, a 53-year-old female. (a) The initial presentation was an impending hole. (b) Vitreomacular separation with vitreofoveal adhesion caused the disruption of the inner lamina and the formation of MH 1 week later. (c) The MH enlarged 1 month later. (d) The MH sealed after vitrectomy. (e-g) Case 7, a 53-year-old male. (e) The initial presentation was lamellar MH with premacular tangential traction. (f) The MH developed 12 months later. (g) The MH sealed after vitrectomy.

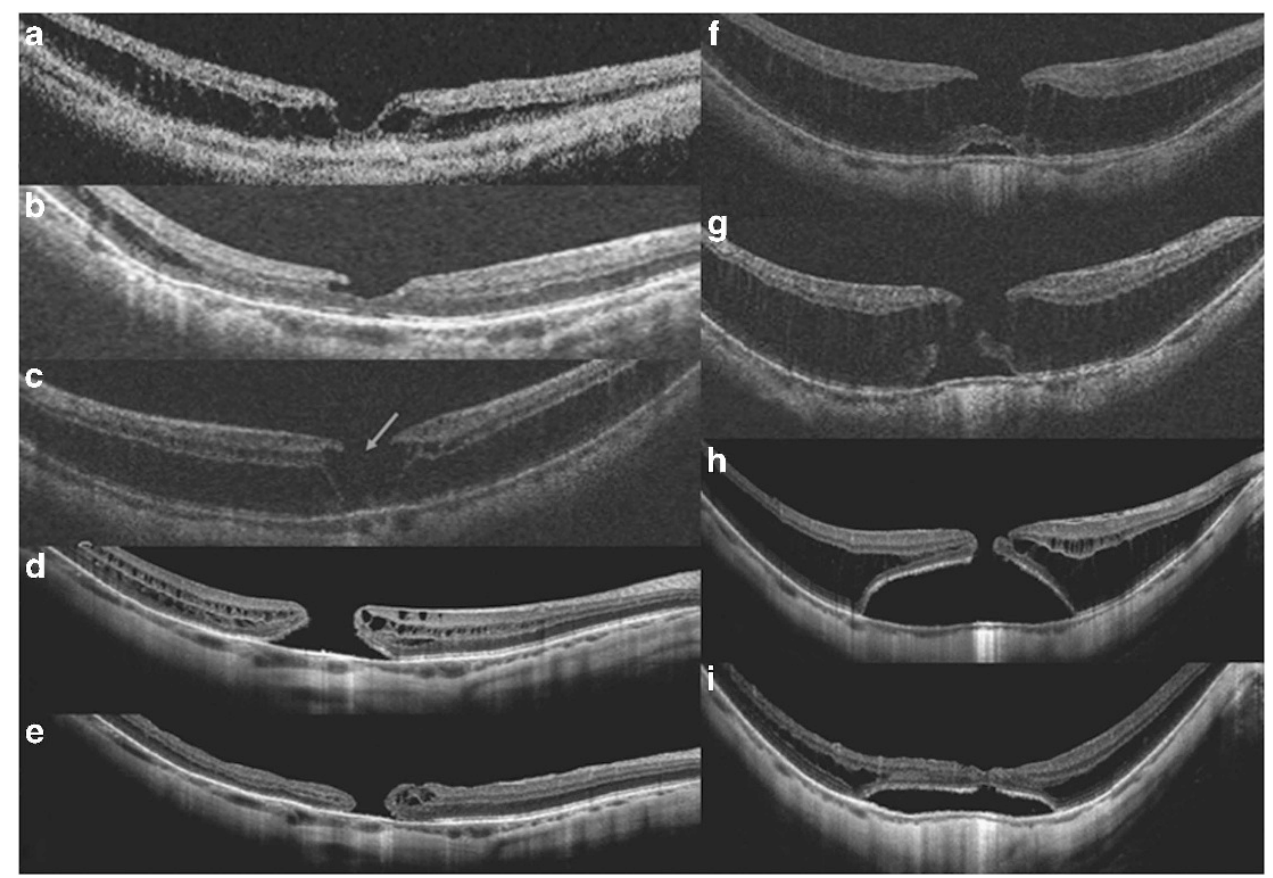

Figure 2 (a-e) Case 14, a 56-year-old male. (a) The initial presentation was schisis on the macular area. (b) The lamellar MH developed 8 months later. (c) Inner lamina dehiscence (arrow) was noted 30 months later. (d) The MH developed 5 months later. The duration from lamellar $\mathrm{MH}$ to $\mathrm{MH}$ formation was 35 months. The height of the schisis decreased and the retina remained attached. (e) The MH persisted after vitrectomy. (f-i) Case 23, a 66-year-old female. (f) The initial presentation was schisis with foveal detachment. (g) Outer lamina disruption developed nine months later. (h) It progressed to $\mathrm{MH}$ with retinal detachment 2 months later. (i) The MH sealed but subretinal fluid remained after vitrectomy.

Type 3: Macular schisis with concomitant or subsequent macular detachment Nine eyes belonged to this type (case 15-23). The average axial length was $30.55 \pm 2.22 \mathrm{~mm}$ (range: $27.45-35.26 \mathrm{~mm}$ ). Two cases (cases 15 and 19) initially presented with schisis only, then developed schisis with macular detachment 3 and
12 months later, respectively. Seven cases of schisis with RD directly advanced to MH with RD (cases 15-17, 19-22); one case developed outer lamina disruption and then progressed to MH with RD (case 23) (Figures 2f-i); another case underwent formation of inner $\mathrm{LMH}$ before developing $\mathrm{MH}$ with RD (case 18). It took 2, 6, 10, 7, 17, 2, 
2, 3, and 11 months, respectively (average: $6.67 \pm 5.2$ months, range: $2-17$ months) to develop $\mathrm{MH}$ from schisis with RD.

Type 4: Macular atrophy with underlying or adjacent submacular scar Three eyes belonged to this type (cases 24-26) (Figure 3). The average axial length was $30.99 \pm 0.54 \mathrm{~mm}$ (range: $30.4-31.47 \mathrm{~mm}$ ). In all three cases, the atrophic macula became thinner, and eventually, FTMH appeared.

The average axial length was longest in type 4 group and shortest in type 2 group. However, there was no significant difference about the axial length between the types of $\mathrm{MH}$ formation $(P=0.771)$.

\section{Macular changes after the development of FTMH}

After MH formation, the macula may stay attached or develop RD. The preexisting RD may also extend beyond the macula area. The following describes the macular changes in our cases during follow-up periods, including the natural course before treatment, the treatment methods, and the results after surgical intervention. Only two of our cases had posterior vitreous detachment noted during surgery (cases 7 and 23).

Type 1: Normal foveal depression with abnormal vitreo-retinal relationship (8 cases, cases 1-8) (1) Abnormal vitreofoveal adhesion with vitreo-macular separation (case 1):

In this group's single case, $\mathrm{MH}$ enlarged within 1 month. Vitrectomy was performed 2 months after $\mathrm{MH}$ formation. The hole was sealed, and best-corrected visual acuity improved from 20/50 before treatment to 20/32 6 months after treatment (Figures 1a-d).

(2) Tangential premacular traction from an ERM (7 cases, cases 2-8):

The macula stayed attached after $\mathrm{MH}$ formation in four cases (cases 2, 4, 6, and 7). Two eyes in this subgroup underwent vitrectomy (cases 2 and 7), but $\mathrm{MH}$ sealed in only one eye (case 7). The other two cases had persistent $\mathrm{MH}$ without RD for more than 15 months.

In two cases, outer schisis developed within 6 and 20 weeks, respectively, with enlargement of the $\mathrm{MH}$ and the surrounding detachment (cases 5 and 8) (Figures 4a-d). Both eyes received vitrectomy and $\mathrm{MH}$ was sealed initially but $\mathrm{MH}$ reopened in one case 15 months later (case 5).

In one case that chose not to have MH surgery, extensive RD developed beyond the macular area 2 years later (case 3) (Figures $4 \mathrm{e}-\mathrm{h}$ ). The retina became reattached but $\mathrm{MH}$ persisted after vitrectomy.

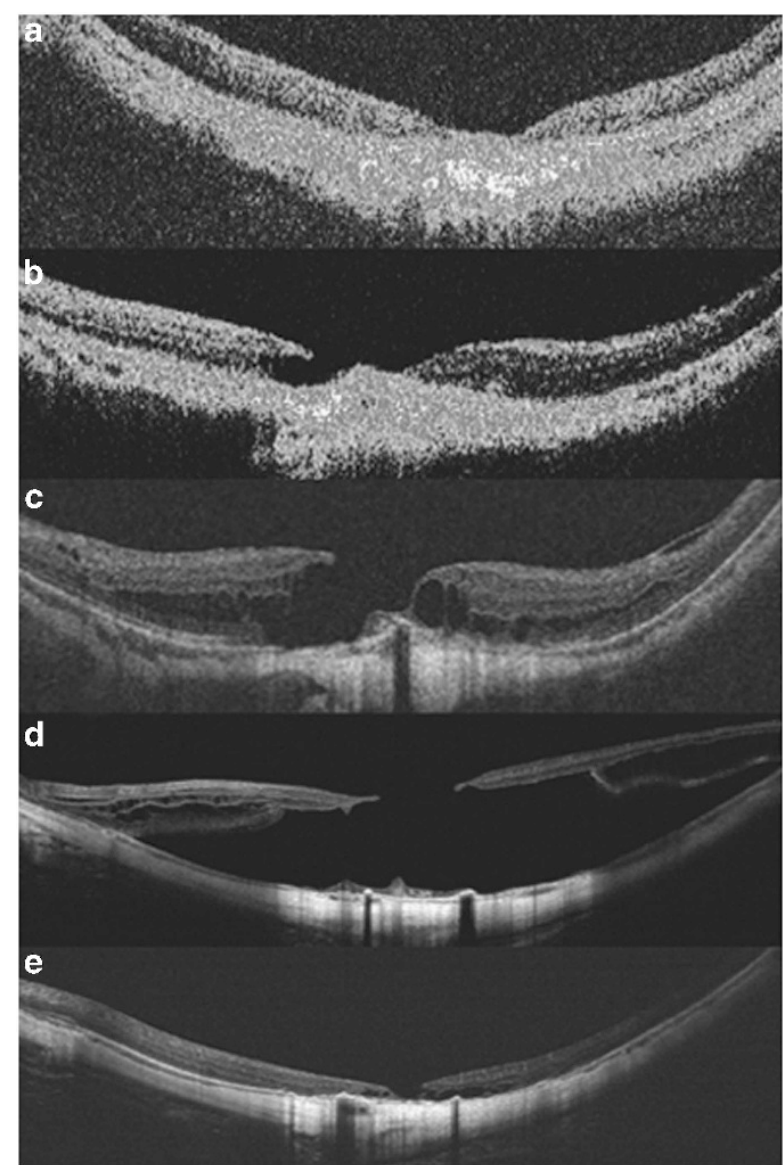

Figure 3 Case 25, a 61-year-old female. (a) The initial presentation was chorioretinal atrophy with macular scar. (b) $\mathrm{MH}$ developed in the area adjacent to the macular scar 18 months later. (c) Macular schisis with epiretinal membrane developed within 2 years after MH formation. (d) It proceeded to macular detachment involving the whole posterior pole 3 years after $\mathrm{MH}$ formation. (e) Retinal reattached but the $\mathrm{MH}$ persisted after three intravitreal injections of C3F8 $0.2 \mathrm{ml}$.

Type 2: Macular schisis without macular detachment (6 cases, cases 9-14) In four cases, RD developed at the same time of $\mathrm{MH}$ formation (cases 10-13). Three cases underwent vitrectomy (cases 10-12) and all regained attachment. MH sealed in two cases (cases 10 and 11), and persisted in one case (case 12). One case received intravitreal injection of $\mathrm{SF}_{6} 0.4 \mathrm{ml}$ and $\mathrm{MH}$ became sealed after the procedure (case 13).

Macula remained attached for more than 2 months after $\mathrm{MH}$ formation in the other two cases (cases 19 and 14) (Figures 2a-e). One case underwent vitrectomy (case 14) but failed to have $\mathrm{MH}$ close.

Type 3: Macular schisis with concomitant or subsequent macular detachment (9 cases, cases 15-23) In eight cases, schisis with RD progressed to $\mathrm{MH}$ with the extension of RD (cases 15-21, 23). In these eight cases, five (cases 15, 


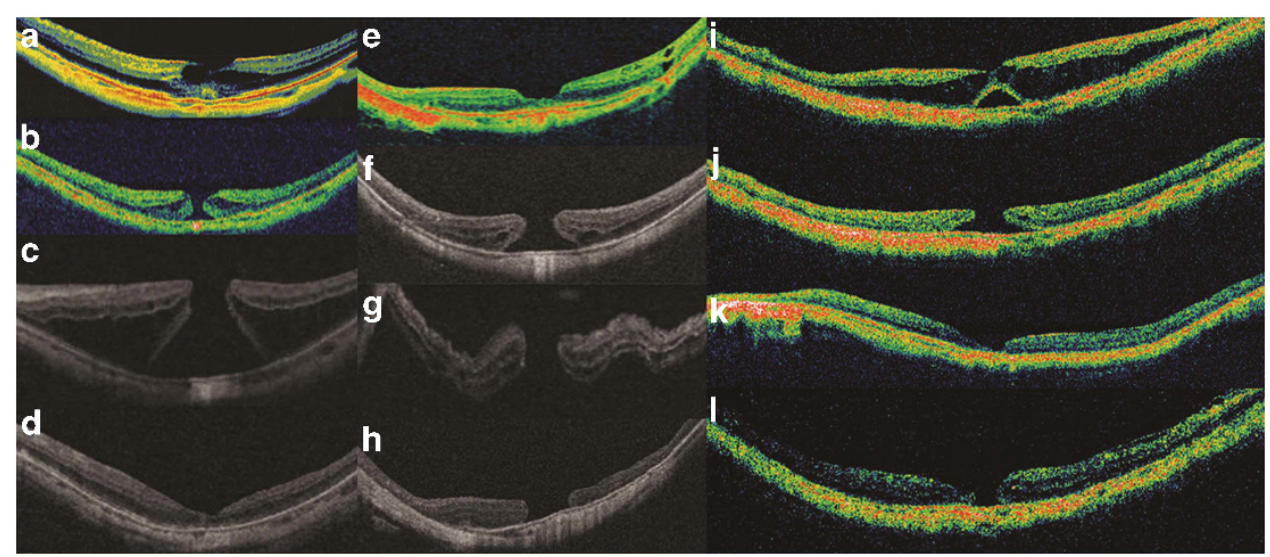

Figure 4 (a-d) Case 5, a 57-year-old female. (a) The initial presentation was lamellar MH. (b) MH developed 2 weeks later. (c) Prominent outer schisis and enlargement of the MH and the surrounding detachment developed within just 6 weeks. (d) The MH sealed after vitrectomy. (e-h) Case 3, a 60-year-old female. (e) The initial presentation was lamellar MH. (f) MH developed 12 months later. (g) The MH with extensive retinal detachment developed 20 months later. (h) The retinal detachment resolved but MH persisted after vitrectomy. (i-1) Case 22, a 46-year-old male. (i) The initial presentation was schisis with retinal detachment. (j) It progressed to $\mathrm{MH}$ with decreased schisis and resolution of retinal detachment 3 months later. (k) The MH sealed after surgery. (l) However, the MH recurred 34 months later.

$17,18,20$, and 21) received intravitreal injection of $\mathrm{C}_{3} \mathrm{~F}_{8}$ $0.2 \mathrm{ml}$. MH sealed with mild schisis in three cases (cases 15,17 , and 18), and the retina reattached but $\mathrm{MH}$ persisted in two cases (cases 20 and 21). Three cases (cases 16, 19, and 23) received vitrectomy; two of them resulted in sealed $\mathrm{MH}$ (cases 19 and 23), but the other one had open $\mathrm{MH}$ despite reattached retina (case 16).

In one case, schisis with RD progressed to $\mathrm{MH}$ with decreased schisis and subretinal fluid (case 22) (Figures 4i-1). Vitrectomy was performed and $\mathrm{MH}$ sealed initially but reopened 34 months later.

Type 4: Macular atrophy with underlying or adjacent submacular scar (3 cases, cases 24-26) MH formation adjacent to a macular scar remained stable for 5 years in two cases (case 24 and 26).

However, in one case, schisis with ERM developed within 2 years after $\mathrm{MH}$ formation (case 25) (Figure 3). It then proceeded to macular detachment involving the whole posterior pole, and though the retina reattached the hole persisted after three times of intravitreal injection of $\mathrm{C}_{3} \mathrm{~F}_{8} 0.2 \mathrm{ml}$.

The initial anatomic success rate of vitrectomy in our study was $64 \%$ (overall: 9 of 14 cases, Type 1 with 4 of 6 cases, Type 2 with 2 of 4 cases, Type 3 with 3 of 4 cases). The anatomic success rate of vitrectomy was $57 \%$ (overall: 4 of 7 cases, Type 2 with 1 of 1 case, Type 3 with 3 of 5 cases, Type 4 with 0 of 1 case). In summary, the overall initial anatomic success rate was 62\% (Type 1: 67\%, Type 2: $60 \%$, Type 3: 67\%, Type 4: $0 \%$ ). The axial length was not correlated with the surgical anatomic outcome $(P=0.568)$.

\section{Discussion}

In this study, we observed through serial OCT images the formation of $\mathrm{MH}$ in high myopia, and noticed that the mechanisms may be similar to those underlying idiopathic $\mathrm{MH}$ in some cases, or unique to high myopic conditions in others. The pre-MH structural changes in the macular area strongly affected the development and evolution pathways of $\mathrm{MH}$ in most high myopic cases.

Similar to idiopathic $\mathrm{MH}$, high myopia eyes may first develop inner foveal cysts with or without small foveal detachment secondary to traction created by vitreofoveal adhesion with vitreomacular separation. The outer laminar disruption followed by inner laminar (inner cyst wall) rupture results in FTMH. Alternatively, the posterior hyaloid may separate from the fovea, bringing forth a piece of retinal tissue and creating an LMH. The development of preretinal membrane may exert tangential traction on the $\mathrm{LMH}$, leading to foveal tissue disruption and FTMH. In this study, a total of eight cases developed $\mathrm{MH}$ through these two pathways; the preretinal membrane-related pathway seemed more commonly seen than occurred in idiopathic condition. In addition, the preretinal membrane may be more widespread than those found in idiopathic cases. ${ }^{12}$ It has been reported that in some cases, a fragment of the nondetached posterior hyaloid or partially split posterior hyaloid (vitreous schisis) may contribute to the preretinal membrane. ${ }^{20}$ This is due to the strong hyaloid retinal adhesion in many high myopic eyes. During surgical repair of the $\mathrm{MH}$ in high myopia, this preretinal tissue can be traced to the periphery in a certain area, continuous with the mid-vitreous hyaloid membrane. ${ }^{12}$ 
When schisis exists in the macular area, the tangential or multi-directional traction from the preretinal membrane may induce tissue disruption of the inner most lining wall of the schisis, leading to an LMH. The continuous traction by the preretinal membrane may finally result in a FTMH. Again, the preretinal membrane may consist of the posterior hyaloid, which contributes to both the LMH and the MH. ${ }^{12}$ The schisis is mostly centrally located, but schisis cavity may also occur in the parafoveal area, as shown in our case 10. Previous research indicates that an average duration of 2 years is expected for the progression of LMH to FTMH in high myopic eyes. ${ }^{15}$ In the present study, the average duration of LMH to FTMH in six cases was about 13 months, but the variation of duration regarding the progression from $\mathrm{LMH}$ to $\mathrm{MH}$ was quite large.

When foveoschisis is combined with foveal detachment, our cases as well as those reported indicate that this change is usually accompanied by the outer laminar dehiscence (or outer LMH). ${ }^{15}$ An FTMH would follow if preretinal traction induces inner laminar dehiscence. In such cases, the $\mathrm{MH}$ is associated with macular detachment. A previous study found that the outer LMH may precede the development of foveal detachment. ${ }^{21}$ Although our study also showed that most cases had outer LMH when foveal detachment occurred, we could not rule out the possibility that the initial event is the foveal detachment, and the outer laminar dehiscence developed later, as shown in our case 23 (Figures 2f-i).

Finally, the formation of MH may be associated with focal chorioretinal atrophy or scar, with the hole occurring in the margin of, or within, the focal macular lesion. ${ }^{22}$ Progressive retinal thinning over the lesion and tangential traction contribute to the hole formation.

The present study shows that after the development of $\mathrm{MH}$, the macular structure might undergo one of the following changes if surgical intervention is not employed shortly. First, the hole may simply become larger, similar to what would be expected in most idiopathic cases. Secondly, macular detachment may occur. Thirdly, the pre-existing macular detachment may expand to involve the posterior pole or even beyond the equatorial area.

In the present study, we found that $\mathrm{MH}$ developing from LMH without schisis was less likely to evolve into detachment. However, we have seen a case of $\mathrm{MH}$ developing from $\mathrm{LMH}$ and then rapidly changing to configurations typical of another pattern, that is, schisis and foveal detachment, within just 6 weeks (case 5) (Figures $4 \mathrm{a}-\mathrm{d}$ ). Previous study showed that $\mathrm{MH}$ related to chorioretinal atrophic lesions or scar was less likely to develop into $\mathrm{RD}^{22}$ however, we found one case where, within 2 years, macular schisis developed after $\mathrm{MH}$ formation; the change then proceeded to macular detachment involving the whole posterior pole in the third year (case 25) (Figure 3), indicating continuous traction exerted to the macula, even in cases with atrophic scar and no detectable vitreo-retinal adhesion. On the other hand, although prominent schisis-related $\mathrm{MH}$ was prone to advance to $\mathrm{MH}$ with macular detachment, we found one case with significant outer retinal schisis progressing to $\mathrm{MH}$, only showing decreased height of the schisis and a persistently attached retina (case 14) (Figures 2a-e). These exceptions highlight the fact that the evolution of $\mathrm{MH}$ is not always predictable.

The MH closure rate after surgery has been found to be affected by many factors, including the presence of foveoschisis, the stage of the hole, the duration of symptoms, the presence of staphyloma, and intraoperative ILM peeling. ${ }^{23-26}$ In high myopia, thin retina with chorioretinal atrophy may impede the diagnosis of $\mathrm{MH}$, and thus delay the timing of intervention. Despite similar surgical approaches, the anatomical outcome after vitrectomy may be very different from series to series. ${ }^{25-29}$ Although it has been shown that longer axial length is associated with more severe traction maculopathy and poorer surgical anatomic outcome, ${ }^{30}$ the case number is too small to provide meaningful statistical analysis on risk factors of persistent $\mathrm{MH}$.

Our study has certain limitations. First, the study was a retrospective longitudinal study; many patients underwent sequential OCTs with different machines during follow-up periods, and surgical interventions were done at different time points after $\mathrm{MH}$ development. Second, the number of cases was relatively small, and the percentage of each category could not reflect the actual distribution of all cases with $\mathrm{MH}$ in high myopia. However, through careful documentation of our limited cases, we were able to observe four different development sequences in the formation of $\mathrm{MH}$ in high myopia. The macular changes after $\mathrm{MH}$ formation were usually related to the pre-hole structural changes; however, $\mathrm{MH}$ evolution may not always be predictable, as in some cases, the configuration that is usually associated with certain pre-hole condition may change to another pattern, revealing the complex forces involved in the development and evolution of $\mathrm{MH}$ in high myopia. Nonetheless, the understanding of the various mechanisms of $\mathrm{MH}$ formation and the usual pattern of the evolution in high myopia may aid in identifying the major forces involved in creating $\mathrm{MH}$ in individual cases, and thus may help in surgical planning and management; the surgical success rate can also be more finely analyzed according to different morphological patterns. Further larger, prospective studies with careful documentation are needed to support our finding and confirm our tentative conclusions. 


\section{Summary}

\section{What was known before}

- The formation of macular hole in high myopia involves vitreomacular traction, traction from epiretinal membrane, internal limiting membrane, and retinal vessel.

- Foveoschisis is one of the main causes of macular hole formation in highly myopic eyes, and is often found in combination with foveal detachment, and lamellar macular hole.

\section{What this study adds}

- We observed four different development sequences in the formation of macular hole in high myopia.

- Although macular holes developed from macular schisis tended to be associated with macular detachment, and macular holes from the other conditions (abnormal vitreo-retinal relationship or macular atrophy) tended to have attached retina, the macular status after macular hole formation was not always predictable.

\section{Conflict of interest}

The authors declare no conflict of interest.

\section{Acknowledgements}

The authors indicated no financial support or conflict of interest.

\section{References}

1 Yeh PT, Chen TC, Yang CH, Ho TC, Chen MS, Huang JS et al. Formation of idiopathic macular hole-reappraisal. Graefes Arch Clin Exp Ophthalmol 2010; 248: 793-798.

2 Miller JB, Yonekawa Y, Eliott D, Vavvas DG. A review of traumatic macular hole: diagnosis and treatment. Int Ophthalmol Clin. 2013; 53(4): 59-67.

3 Yeh PT, Cheng CK, Chen MS, Yang CH, Yang CM. Macular hole in proliferative diabetic retinopathy with fibrovascular proliferation. Retina 2009; 29(3): 355-361.

4 Smiddy WE, Flynn Jr., HW. Pathogenesis of macular holes and therapeutic implications. Am J Ophthalmol 2004; 137(3): 525-537.

5 Shih YH, Chiang TH, Hsiao CK, Chen CJ, Hung PT, Lin LK. Comparing Myopic Progression of Urban and Rural Taiwanese School children. Jpn J Ophthalmol 2010; 54: 446-451.

6 Stripe M, Michels RG. Retinal detachment in highly myopic eyes duo to macular holes and epiretinal traction. Retina 1990; 10: 113-114.

7 Oshima Y, Ikuno Y, Motokura M, Nakae K, Tano Y. Complete epiretinal membrane separation in highly myopic eyes with retinal detachment resulting from a macular hole. Am J Ophthalmol 1998; 126: 669-676.

8 Seike C, Kusaka S, Sakagami K, Ohashi Y. Reopening of macular holes in highly myopic eyes with retinal detachments. Retina 1997; 17: 2-6.

9 Sayanagi K, Oshima Y, Ikuno Y, Tano Y. Presumed vascular traction-associated recurrence of retinal detachment in patients with myopic macular hole. Ophthalmic Surg Lasers Imaging 2009; 40(1): 60-64.

10 Morita H, Ideta H, Ito K, Yonemoto J, Sasaki K, Tanaka S. Causative factors of retinal detachment in macular holes. Retina 1991; 11: 281-284.

11 Smiddy WE, Kim SS, Lujan BJ, Gregori G. Myopic traction maculopathy: spectral domain optical coherence tomographic imaging and a hypothesized mechanism. Ophthalmic Surg Lasers Imaging 2009; 40: 169-173.

12 Gaucher D, Haouchine B, Tadayoni R, Massin P, Erginay A, Benhamou $\mathrm{N}$ et al. Long-term follow-up of high myopic foveoschisis: natural course and surgical outcome. Am J Ophthalmol 2007; 143: 455-462.

13 Shimada N, Ohno-Matsui K, Baba T, Futagami S, Tokoro T, Mochizuki M. Natural course of macular retinoschisis in highly myopic eyes without macular hole or retinal detachment. Am J Ophthalmol 2006; 142: 497-500.

14 Benhamou N, Massin P, Haouchine B, Erginay A, Gaudric A. Macular retinoschisis in highly myopic eyes. Am J Ophthalmol 2002; 133: 794-800.

15 Sun CB, Liu Z, Xue AQ, Yao K. Natural evolution from macular retinoschisis to full-thickness macular hole in highly myopic eyes. Eye 2010; 24: 1787-1791.

16 Chen FT, Yeh PT, Lin CP, Chen MS, Yang CH, Yang CM. Intravitreal gas injection for macular hole with localized retinal detachment in highly myopic patients. Acta Ophthalmol 2011; 89(2): 172-178.

17 Wu TY, Yang CH, Yang CM. Gas tamponade for myopic foveoschisis with foveal detachment. Graefes Arch Clin Exp Ophthalmol 2013; 251(5): 1319-1324.

18 Kao TY, Yang CM, Yeh PT, Huang JY, Yang CH. The value of combining autofluorescence and optical coherence tomography in predicting the visual prognosis of sealed macular holes. Am J Ophthalmol 2013; 156(1): 149-156.

19 Wu CM, Yeh PT, Yang CH, Chen MS, Yang CM. Comparison of triamcinolone and VisCoat in indocyanine-green-assisted internal-limiting-membrane peeling in macular hole surgery. Taiwan J Ophthalmol 2013; 3: 20-25.

20 Duker JS, Kaiser PK, Binder S, de Smet MD, Gaudric A, Reichel $\mathrm{E}$ et al. The International Vitreomacular Traction Study Group classification of vitreomacular adhesion, traction, and macular hole. Ophthalmology 2013; 120(12): 2611-2619.

21 Shimada N, Ohno-Matsui K, Yoshida T, Sugamoto Y, Tokoro T, Mochizuki M. Progression from macular retinoschisis to retinal detachment in highly myopic eyes is associated with outer lamellar hole formation. Br J Ophthalmol. 2008; 92(6): 762-764.

22 Shimada N, Ohno-Matsui K, Yoshida T, Futagami S, Tokoro T, Mochizuki M. Development of macular hole and macular retinoschisis in eyes with myopic choroidal neovascularization. Am J Ophthalmol. 2008; 145(1): 155-161.

23 Jaycock PD, Bunce C, Xing W, Thomas D, Poon W, Gazzard G et al. Outcomes of macular hole surgery: implications for surgical management and clinical governance. Eye 2005; 19(8): 879.

24 Ezra E, Gregor ZJ. Surgery for idiopathic full-thickness macular hole: two-year results of a randomized clinical trial comparing natural history, vitrectomy, and vitrectomy plus autologous serum: Morfields Macular Hole Study Group Report no. 1. Arch Ophthalmol 2004; 122(2): 224-236.

25 Alkabes M, Pichi F, Nucci P, Massaro D, Dutra Medeiros M, Corcostegui $\mathrm{B}$ et al. Anatomical and visual outcomes in high myopic macular hole (HM-MH) without retinal 
detachment: a review. Graefes Arch Clin Exp Ophthalmol 2014 252(2): 191-199.

26 Kwok AKH, Lai TYY. Internal limiting membrane removal in macular hole surgery for severely myopic eyes: a case-control study. Br J Ophthalmol 2003; 87: 885-889.

27 Sulkes DJ, Smiddy WE, Flynn HW, Feuer W. Outcomes of macular hole surgery in severely myopic eyes: a case-control study. Am J Ophthalmol 2000; 130: 335-339.

$28 \mathrm{Wu}$ TT, Kung YH. Comparison of anatomical and visual outcomes of macular hole surgery in patients with high myopia vs. non-high myopia: a case-control study using optical coherence tomography. Graefes Arch Clin Exp Ophthalmol 2012; 250: 327-331.

29 Alkabes M, Padilla L, Salinas C, Nucci P, Vitale L, Pichi $\mathrm{F}$ et al. Assessment of OCT measurements as prognostic factors in myopic macular hole surgery without foveoschisis. Graefes Arch Clin Exp Ophthalmol 2013; 251(11): 2521-2527.

30 Suda K, Hangai M, Yoshimura N. Axial length and outcomes of macular hole surgery assessed by spectral-domain optical coherence tomography. Am J Ophthalmol 2011; 151(1): 118-127. 